\title{
Pimecrolimus Cream 1\% for the Treatment of Papulopustular Eruption Related to Epidermal Growth Factor Receptor Inhibitors: A Case Series and a Literature Review of Therapeutic Approaches
}

\author{
$\begin{array}{llll}\text { V. Nikolaou } & \text { A. Stratigos } & \text { a } & \text { C. Antoniou } \\ \text { a } & \text { M. Kiagia } & \text { C. Nikolaou } & \text { A. Katsambas } \\ & \text { a }\end{array}$ \\ K. Syrigos ${ }^{b}$ \\ a Department of Dermatology, A. Sygros Hospital, and bepartment of Oncology, Sotiria General Hospital, \\ University of Athens Medical School, Athens, Greece
}

\section{Key Words}

Pimecrolimus - Epidermal growth factor receptor inhibitors · Acneiform eruption · Erlotinib $\cdot$ Cetuximab

\footnotetext{
Abstract

Background: Cutaneous side effects of epidermal growth factor receptor inhibitors (EGFRIs) are very frequent and well known. The aim of our study was to investigate the efficacy and safety of pimecrolimus 1\% cream in the treatment of papulopustular eruption caused by EGFRIs and to review the relevant literature on therapeutic approaches. Methods: Twenty cancer patients being treated with EGFRIs were included in the study. Nine of the patients showed grade 1 and 11 showed grade 2 papulopustular eruption. All patients were treated with pimecrolimus $1 \%$ cream, which was applied twice daily. Patients with grade 2 eruption also received systemic minocycline $100 \mathrm{mg} /$ day. Results: All patients with grade 1 eruption responded to treatment, with 4/9 experiencing complete resolution of the lesions 2 weeks after the initiation of treatment. Five out of 11 patients with grade 2 eruption had
}

more than $50 \%$ improvement in erythema and pustules, and 1 had complete resolution of the skin lesions. Two patients did not respond to treatment but were significantly improved after substitution of pimecrolimus $1 \%$ cream with metronidazole $1 \%$ cream. No side effects were recorded. Conclusions: Ourcaseseries shows that pimecrolimus cream may be an effective and safe approach in the management of papulopustular eruption related to EGFRIs.

Copyright $\odot 2010$ S. Karger AG, Basel

\section{Introduction}

Epidermal growth factor receptor inhibitors (EGFRIs) are novel anticancer treatments, effective for patients with nonsmall-cell lung cancer, head and neck cancer, and other malignancies [1-3]. Erlotinib (Tarceva) and cetuximab (Erbitux) are two of the most commonly used antiEGFR agents, whereas others are under development. EGFRIs are generally well tolerated and do not have any of the severe systemic side effects seen with 'traditional' cytotoxic agents. However, these agents have been associated with major cutaneous side effects $[4,5]$. Papulopustular eruption is the most common skin toxicity and occurs at a rate of $45-100 \%$ of treated patients, depending on the agent. It presents more frequently as a monomorphic acneiform rash in the seborrhoeic areas of the face, neck, shoulders, upper trunk and scalp. Unlike acne, EGFRI-induced rash is usually pruritic and is characterized by the lack of comedones.

Several agents have been used to treat the cutaneous side effects of EGFRIs, and their efficacy has been assessed in a few randomized controlled trials. Prophylactic management with tetracycline $500 \mathrm{mg}$ b.i.d. reduces the severity of the papulopustular reaction but has no effect on the incidence of the skin rash [6]. In addition, minocycline at a dose of $100 \mathrm{mg}$ b.i.d. has been shown to reduce the number of papulopustular lesions [7]. A variety of topical agents has also been used especially for grade 1 reactions. Topical corticosteroids can be effective in the management of cutaneous reactions but the need for highpotency formulations may lead to side effects, especially when applied in sensitive

\section{KARGER}

Fax +4161306 1234 E-Mail karger@karger.ch www.karger.com
Vasiliki A. Nikolaou, MD

Andreas Sygros Hospital

5 Dragoumi Street

GR-10671 Athens (Greece)

Tel. +30 210361 2231, Fax +30 210362 2467, E-Mail drviknik@yahoo.com 
Fig. 1. Papulopustular eruption before (a) and after (b) combination treatment (minocycline $100 \mathrm{mg} / \mathrm{day}+$ pimecrolimus $1 \%$ cream).
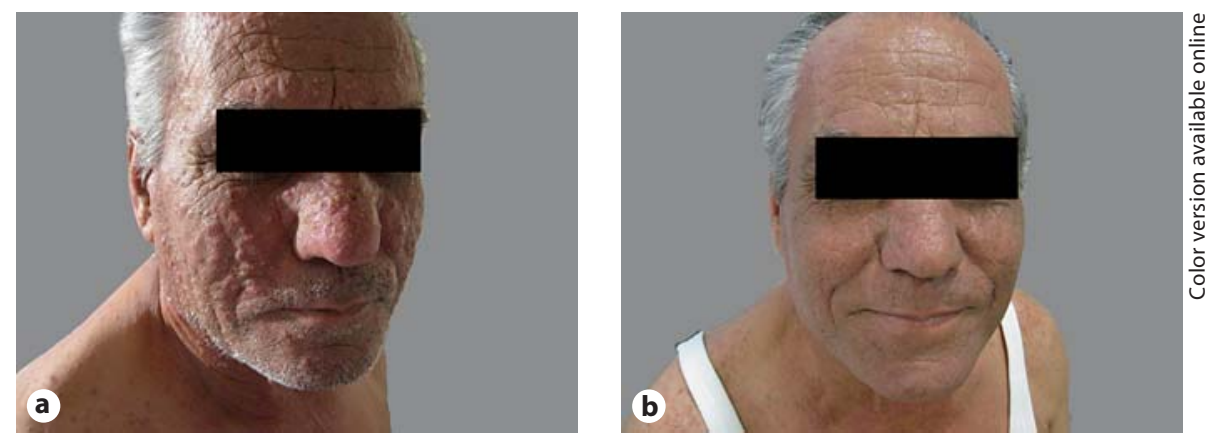

areas such as the face [8]. Topical anti-acne treatments such as retinoids, benzoyl peroxide and clindamycin gel have also been reported to be effective, but their use is not tolerated well due to frequent skin irritation and dryness [9].

Pimecrolimus is an ascomycin macrolactam derivative that exerts a powerful anti-inflammatory action, predominantly by targeting the cutaneous T-cell-mediated inflammatory response [10]. By preventing calcineurin-mediated dephosphorylation of the nuclear factor of activated T cells, it inhibits synthesis of Thelper 1 and 2 cytokines from $\mathrm{T}$ cells. It has a lower permeation through the skin than topical steroids and does not produce skin atrophy [11]. The purpose of the present study is to assess the efficacy and tolerability of topical pimecrolimus in a series of patients with papulopustular eruption caused by treatment with EGFRIs and to review the recent literature data on the treatment of EGFRI-related papulopustular eruption.

\section{Patients and Methods}

The study included 20 patients treated with an EGFRI who presented with an associated papulopustular eruption. The classification proposed by the National Cancer Institute Common Toxicity Criteria, version 3.0, was used for patient grading. All patients developed papulopustular eruption grade 1 or 2 . Grade 1 was defined as localized asymptomatic follicular pustules. Grade 2 was defined as itchy localized pustules involving $<50 \%$ of the total body area. Each patient was treated with pimecrolimus 1\% cream (Elidel; Novartis Pharma, Switzerland), applied twice daily in a thin layer for at least 2 weeks. Patients with grade 1 eruption were treated with pimecrolimus cream, whereas for patients with grade 2 eruption minocycline 100 $\mathrm{mg} /$ day was added. Pimecrolimus cream was used for a maximum of a 6-week period. The therapeutic responses were evaluated based on the reduction of erythema, pustules and pruritus and graded as no response, $<50 \%$ reduction, $>50 \%$ reduction or complete clearance of papulopustular eruption. Any side effect related to the use of pimecrolimus was routinely recorded. Clinical examination and recording of each patient's symptoms was performed by the same physician (V.N.) before and every 2 weeks of therapy.

This prospective clinical study was approved by an Institutional Review Board of Sotiria General Hospital, Athens, Greece. Before commencing treatment, all patients were informed that pimecrolimus cream $1 \%$ had not yet been approved for use in this particular skin disorder, and all patients understood that the use of this agent for EGFR skin toxicities is an unlicensed indication. All patients signed a consent form in order to participate in the study.

\section{Results}

Twenty patients ( 5 women and 15 men) with non-small-cell lung cancer $(\mathrm{n}=14)$, head and neck squamous cell carcinoma $(n=4)$ and colorectal cancer $(n=2)$ were treated. The mean age of the patients was 67.2 years (range 49-79 years). Fourteen patients were under erlotinib treatment, 5 patients were under cetuximab, and 1 patient was treated with panitumumab. Of these, 9 had grade 1 eruption and were treated with pimecrolimus cream alone, and 11 had grade 2 eruption and were treated with a combination of minocycline $100 \mathrm{mg} /$ day and topical pimecrolimus $1 \%$ cream. Seven out of 20 patients had previously been treated with potent topical corticosteroids whereas 2 patients had been treated with topical metronidazole cream, mostly cream based, without a satisfying effect. For the rest of the patients, pimecrolimus was the first topical treatment used for their eruption.

Table 1 summarizes the response to treatment in each of the 20 patients during weeks 2, 4 and 6 . All patients tolerated treatment without any complaints of mild burning or stinging. Of the 9 patients with grade 1 eruption, 4 had a complete response and 4 had $>50 \%$ improvement in erythema and pustules in week 2 . One additional patient (No. 4) had been using metronidazole cream on the face and pimecrolimus cream on the back, and both treatments were moderately effective with a response rate of $<50 \%$. Five out of 11 patients treated with the combination of minocycline and pimecrolimus achieved a response rate of $>50 \%$ while 1 patient had complete clearance of his rash in week 2 (fig. 1). Of the 2 non-responders, 1 (patient No. 11) had been treated with metronidazole cream on the face and pimecrolimus cream on the back. Metronidazole cream was effective with a $>50 \%$ improvement on the facial skin rash whereas pimecrolimus cream was not effective. The second non-responder (patient No. 3) achieved $>50 \%$ reduction of the rash 2 weeks after application of metronidazole cream. In week 6,8 patients had stopped treatment, due to lack of efficacy (3 patients), were lost to followup (1 patient), experienced EGFRI-related toxicity (2 patients) or had other disease complications (2 patients). 
Table 1. Response to pimecrolimus application in weeks 2, 4 and 6

\begin{tabular}{|c|c|c|c|c|c|c|c|}
\hline Patient No. & Sex & Cancer & EGFRI & Previous therapy & RR: 2 weeks & RR: 4 weeks & RR: 6 weeks \\
\hline \multicolumn{8}{|c|}{ Grade 1: pimecrolimus cream } \\
\hline 1 & $\mathrm{~F}$ & head and neck & cetuximab & Crds & CR & CR & CR \\
\hline 2 & $\mathrm{M}$ & NSCLC & erlotinib & Crds & $>50 \%$ & $>50 \%$ & $>50 \%$ \\
\hline 3 & $\mathrm{~F}$ & NSCLC & erlotinib & Crds & CR & $\mathrm{CR}$ & $\mathrm{CR}$ \\
\hline 4 & M & NSCLC & erlotinib & NT & $<50 \%$ & $>50 \%$ & $<50 \%$ \\
\hline 5 & M & NSCLC & erlotinib & NT & $>50 \%$ & $>50 \%$ & $>50 \%$ \\
\hline 6 & $\mathrm{~F}$ & NSCLC & erlotinib & NT & CR & $\mathrm{CR}$ & CR \\
\hline 7 & $\mathrm{M}$ & head and neck & cetuximab & NT & $>50 \%$ & $>50 \%$ & NA \\
\hline 8 & $\mathrm{~F}$ & NSCLC & erlotinib & NT & CR & CR & CR \\
\hline 9 & $\mathrm{M}$ & NSCLC & erlotinib & Crds & $>50 \%$ & $>50 \%$ & NA \\
\hline \multicolumn{8}{|c|}{ Grade 2: pimecrolimus cream + minocycline $100 \mathrm{mg} /$ day } \\
\hline 1 & $\mathrm{M}$ & NSCLC & erlotinib & NT & $>50 \%$ & $>50 \%$ & $<50 \%$ \\
\hline 2 & $\mathrm{~F}$ & NSCLC & erlotinib & Crds & $>50 \%$ & $>50 \%$ & NA \\
\hline 3 & $\mathrm{M}$ & NSCLC & erlotinib & NT & NR & NR & NA \\
\hline 4 & $\mathrm{M}$ & colorectal cancer & panitumumab & NT & CR & CR & CR \\
\hline 5 & $\mathrm{M}$ & colorectal cancer & cetuximab & Crds & $<50 \%$ & $<50 \%$ & NA \\
\hline 6 & M & NSCLC & erlotinib & Crds & $<50 \%$ & $<50 \%$ & $<50 \%$ \\
\hline 7 & $\mathrm{M}$ & head and neck & cetuximab & NT & $>50 \%$ & $>50 \%$ & $>50 \%$ \\
\hline 8 & $\mathrm{M}$ & NSCLC & erlotinib & NT & $>50 \%$ & $>50 \%$ & NA \\
\hline 9 & $\mathrm{M}$ & NSCLC & erlotinib & Mtr & $>50 \%$ & $>50 \%$ & NA \\
\hline 10 & M & NSCLC & erlotinib & Mtr & $<50 \%$ & $<50 \%$ & NR \\
\hline 11 & $\mathrm{M}$ & head and neck & cetuximab & NT & NR & NA & NA \\
\hline
\end{tabular}

$\mathrm{RR}=$ Response rate; $\mathrm{M}=$ male; $\mathrm{F}=$ female NSCLC = non-small-cell lung cancer; Crds = topical corticosteroids; $\mathrm{NT}=$ no treatment; $\mathrm{Mtr}=$ topical metronidazole; $\mathrm{NR}=$ no response; $\mathrm{CR}=$ complete response; $\mathrm{NA}=$ not applicable, discontinuation of topical or EGFRI treatment.

\section{Discussion}

Papulopustular eruption is a common side effect that the clinician is often confronted with in the context of anti-EGFR treatment. At present, there is a clear medical need for supportive dermatological treatments that will accompany these novel anticancer treatment modalities, in order to improve patient compliance as well as health-related quality of life. So far, the management of EGFRI-mediated skin rash is based principally on expert opinion, and only a few case series and even fewer randomized studies evaluating treatment strategies have been published (table 2).

The interventions suggested for EGFRI-associated cutaneous toxicity are based on the severity of the reaction. For grade 1 reactions, topical antibiotics have been used and in many centres are considered the treatment of choice [18]. Metronidazole is preferred because it is normally used for the very sensitive skin of rosacea patients, a condition that shares common characteristics with the EGFRI-related papulopustular eruption [18]. It can be applied twice daily and acts quite rapidly and effectively for papulopustular lesions. For an acute pustular or oedematous reaction, drying components such as topical $2 \%$ clindamycin may be an alternative effective option [8].

It has been suggested that the use of a low- to medium-potency topical steroid further enhances treatment of mild to severe rash by inhibiting inflammation [19]. In our experience, high-potency topical corticosteroids are only moderately effective in the management of these skin reactions and the long-term use in sensitive areas, such as the face, may lead to undesirable side effects, i.e. steroid-induced acne, atrophy of the skin, striae and telangiectasia. However, in skin areas more resistant to steroid side effects, such as the scalp, local corticosteroids can be used intermittently. Topical tretinoin, benzoyl peroxide gel and other anti-acne therapies are usually avoided because of the lack of a comedonal component in EGFRI-related eruption and the potential aggravation of skin dryness even though its efficacy has been advocated in some reports [20].

For moderate to severe skin toxicity (grade 2), the oral semisynthetic tetracycline antibiotics minocycline and doxycycline are recommended in addition to the topical treatments already described. Although EGFRI-mediated skin toxicity does not seem to involve infectious agents, the anti-inflammatory properties of tetracyclines, through their inhibitory action on matrix metalloproteinase, may partially explain their effectiveness [21, 22]. These agents are given over a course of at least 4-6 weeks and are usually well tolerated, with a reduction of lesional number and severity within 1-2 weeks. Isotretinoin is not routinely recommended be- 
Table 2. Summary of published studies evaluating treatment strategies for skin toxicity mediated by EGFRIs

\begin{tabular}{|c|c|c|c|c|}
\hline Reference & Treatment & Study design & Patients & Comments \\
\hline $\begin{array}{l}\text { Gutzmer } \\
\text { et al. [12], } 2005\end{array}$ & Isotretinoin & Case reports & 2 & $\begin{array}{l}\text { Improvement within } 4 \text { weeks of treatment } \\
\text { Dryness was well tolerated } \\
\text { Paronychia noted in } 1 \text { patient }\end{array}$ \\
\hline $\begin{array}{l}\text { Lacouture } \\
\text { et al. [13], } 2006\end{array}$ & $\begin{array}{l}\text { Doxycycline }+ \\
\text { pimecrolimus cream }\end{array}$ & Case report & 1 & $\begin{array}{l}\text { Resolution of pustules, no facial tenderness at } 2 \text { weeks of } \\
\text { follow-up }\end{array}$ \\
\hline $\begin{array}{l}\text { Matheis } \\
\text { et al. [14], } 2006\end{array}$ & $\begin{array}{l}\text { Tetracycline }+ \\
\text { metronidazole } \\
0.75 \% \text { cream }\end{array}$ & Case reports & 3 & $\begin{array}{l}\text { Improvement achieved in all patients } \\
\text { Monotherapy with metronidazole } 0.75 \% \text { cream was } \\
\text { ineffective in } 2 \text { patients }\end{array}$ \\
\hline $\begin{array}{l}\text { Scope } \\
\text { et al. [7], } 2007\end{array}$ & $\begin{array}{l}\text { Minocycline }+ \\
\text { topical tazarotene } \\
\text { versus placebo }\end{array}$ & $\begin{array}{l}\text { Placebo-controlled } \\
\text { double-blinded }\end{array}$ & 48 & $\begin{array}{l}\text { Preventive treatment } \\
\text { Fewer total facial lesion counts } \\
\text { Reduced moderate to severe itch } \\
\text { Topical tazarotene associated with significant irritation }\end{array}$ \\
\hline $\begin{array}{l}\text { Alexandrescu } \\
\text { et al. [15], } 2007\end{array}$ & $\begin{array}{l}\text { Colloidal oatmeal } \\
\text { lotion }\end{array}$ & Case series & 11 & $\begin{array}{l}\text { Complete resolution of lesions in } 6 \text { patients, partial } \\
\text { resolution in } 4 \text { patients }\end{array}$ \\
\hline $\begin{array}{l}\text { De Witt } \\
\text { et al. [16], } 2007\end{array}$ & $\begin{array}{l}\text { Tetracyclines + } \\
\text { adapalene } \\
\text { Isotretinoin }\end{array}$ & Case reports & 2 & $\begin{array}{l}\text { Reduction in lesions with combination treatment } \\
\text { Dramatic clearance with low-dose isotretinoin }\end{array}$ \\
\hline $\begin{array}{l}\text { Jatoi } \\
\text { et al. [6], } 2008\end{array}$ & $\begin{array}{l}\text { Tetracycline versus } \\
\text { placebo }\end{array}$ & $\begin{array}{l}\text { Placebo-controlled } \\
\text { double-blinded }\end{array}$ & 61 & $\begin{array}{l}\text { Preventive treatment } \\
\text { Reduction in rash severity } \\
\text { Improved burning, stinging and skin irritation }\end{array}$ \\
\hline $\begin{array}{l}\text { Pomerantz } \\
\text { et al. [17], } 2008\end{array}$ & Acitretin & Case report & 1 & $\begin{array}{l}\text { Complete resolution of papulopustular eruption after } \\
1 \text { month of treatment } \\
\text { No relapse for } 6 \text { months }\end{array}$ \\
\hline
\end{tabular}

cause of its known interaction with the antitumoural properties of EGFRIs and their known adverse events, i.e. xerosis or paronychia, that may aggravate the already established cutaneous toxicity induced by EGFRIs. However, in cases where the first-line interventions have failed and when evidence of tumour response to the EGFRIs has been demonstrated, the use of low-dose oral isotretinoin may be considered and can be effective [12]. Systemic steroids are not routinely recommended; however, they could be administered for papulopustular eruptions that have not improved despite 2 weeks of high-dose tetracycline therapy. Short courses of prednisone $(0.35-0.5 \mathrm{mg} / \mathrm{kg}$ q.d.) can be effective in controlling flares but it should be noted that the immunomodulatory effects of steroids on the EGFRIs are not known [23].
The therapeutic approach for grade 3 reaction does not differ from that for grade 2 skin reaction. Superinfection by Staphylococcus aureus is not uncommon and when suspected should be confirmed by a swab for bacterial culture and treated with systemic anti-S.-aureus antibiotics. If there is no improvement despite appropriate dermatological support, the administration of the EGFRI should be discontinued or its dose should be decreased according to treatment protocols.

Topical calcineurin inhibitors, i.e. pimecrolimus and tacrolimus, are new agents that provide an effective and safe alternative option, for chronic inflammatory skin diseases such as atopic dermatitis. Pimecrolimus has been successfully used in various inflammatory skin diseases, including seborrhoeic dermatitis, intertriginous psoriasis, facial psoriasis, li- chen planus, vitiligo and cutaneous lupus erythematosus [24, 25]. To our knowledge, this is the first case series of patients under EGFRIs treated with pimecrolimus 1\% cream. Lacouture et al. [13] reported a case of a 55-year-old female patient diagnosed with a non-small-cell lung cancer who was treated with $50 \mathrm{mg}$ doxycycline twice daily and topical pimecrolimus cream. The patient achieved resolution of pustules 2 weeks after the initiation of treatment. In concordance to their findings, our patients responded either to topical or combination treatment 2 weeks after the initiation of treatment, with no further improvement noted with the continuation of treatment. To our knowledge, there are no case series of effective second-line agents in the treatment of EGFRI-related cutaneous toxicities with which to compare our data. Overall, patients with grade 1 reaction had a 
higher response rate to treatment compared to patients with grade 2 reactions. However, the number of patients treated was small, and one can exclude the possibility of spontaneous resolution, which is known to occur in some cases.

The overall response rate to pimecrolimus cream was satisfying, and treatment was well tolerated. Moreover, pimecrolimus cream was beneficial in 1 patient who failed to respond to metronidazole cream. A major advantage of pimecrolimus is the lack of the side effects seen with other anti-inflammatory agents such as topical corticosteroids or anti-acne formulations. However, a concern exists about the potential carcinogenic risk of topical calcineurin inhibitors with respect to skin malignancies and lymphomas. There is recent evidence that pimecrolimus is not associated with an increased risk of non-melanoma skin cancer [26] or lymphoma in immunocompetent individuals in com- parison to other topical agents including corticosteroids [27]. However, it is not clear whether the same holds true for immunosuppressed individuals.

The pathogenesis of cutaneous reactions caused by EGFR antagonists is incompletely characterized. EGFR plays a key role in the physiological function of keratinocytes, stimulating epidermal growth, protecting against ultraviolet-induced damage and inhibiting inflammation. It has been shown (in vitro) that EGFRIs have a direct effect on the release of inflammatory chemokines, which can initiate release of cytokines and enzymes that cause keratinocyte apoptosis [28]. The exact mechanism by which pimecrolimus may be effective in the treatment of papulopustular eruption is unclear. Inhibition of pimecrolimus-inhibited inflammatory mediators may be a possible mechanism, although histological and experimental evidence for this hypothesis is lacking.
The limitation of our prospective study relates to the small number of patients and open non-randomized design. Randomized controlled trials as well as the application of a more accurate grading system of EGFRI-related eruptions are needed in order to evaluate the effectiveness of such treatments. In our view, the use of topical metronidazole and oral tetracyclines should be the first-line treatment. Based on our findings, pimecrolimus cream may be a viable option for the treatment of skin toxicities when first-line treatment has failed or has been poorly tolerated. Overall, management of EGFRI-related skin rash should be individualized, depending on the type, severity and extent of the eruption caused by EGFRIs. Rational treatment strategies for EGFRi-related skin toxicity are strongly needed, as the use of these agents is expanding in clinical oncology.

\section{References}

-1 Shepherd FA, Rodriques Pereira J, Ciuleanu T, Tan EH, Hirsh V, Thongprasert S, Campos D, Maoleekoonpiroj S, Smylie M, Martins R, van Kooten M, Dediu M, Findlay B, Tu D, Johnston D, Bezjak A, Clark G, Santabárbara P, Seymour L, National Cancer Institute of Canada Clinical Trials Group: Erlotinib in previously treated non-small cell lung cancer. N Engl J Med 2005;353:123-132.

-2 Saltz LB, Meropol NJ, Loehrer PJ Sr, Needle MN, Kopit J, Mayer RJ: Phase II trial of cetuximab in patients with refractory colorectal cancer that expresses the epidermal growth factor receptor. J Clin Oncol 2004;22: 1201-1208.

-3 Bonner JA, Harari PM, Giralt J, Azarnia N, Shin DM, Cohen RB, Jones CU, Sur R, Raben D, Jassem J, Ove R, Kies MS, Baselga J, Youssoufian H, Amellal N, Rowinsky EK, Ang KK: Radiotherapy plus cetuximab for squamous cell carcinoma of the head and neck. N Engl J Med 2006;354:567-578.

4 Duvic M: EGFR inhibitor-associated acneiform folliculitis: assessment and management. Am J Clin Dermatol 2009;9:285-294.

-5 Rigopoulos D, Gregoriou S, Belyayeva Y, Larios G, Gkouvi A, Katsambas A: Acute paronychia caused by lapatinib therapy. Clin Exp Dermatol 2009;34:94-95.
-6 Jatoi A, Rowland K, Sloan JA, Gross HM, Fishkin PA, Kahanic SP, Novotny PJ, Schaefer PL, Johnson DB, Tschetter LK, Loprinzi CL: Tetracycline to prevent epidermal growth factor receptor inhibitor-induced skin rashes: results of a placebo-controlled trial from the North Central Cancer Treatment Group (N03CB). Cancer 2008;113: 847-853.

7 Scope A, Agero AL, Dusza SW, Myskowski PL, Lieb JA, Saltz L, Kemeny NE, Halpern AC: Randomized double-blind trial of prophylactic oral minocycline and topical tazarotene for cetuximab-associated acne-like eruption. J Clin Oncol 2007;25:5390-5396.

8 Shah N, Kris M, Pao W, Tyson LB, Pizzo BM, Heinemann MH, Ben-Porat L, Sachs DL, Heelan RT, Miller VA: Practical management of patients with non-small cell lung cancer treated with gefitinib. J Clin Oncol 2005;23:165-174.

-9 Segaert S, Van Cutsem E: Clinical signs, pathophysiology and management of skin toxicity during therapy with epidermal growth factor receptor inhibitors. Ann Oncol 2005; 16:1425-1433.

10 Grassberger M, Baumruker T, Enz A, Hiestand P, Hultsch T, Kalthoff F, Schuler W, Schulz M, Werner FJ, Winiski A, Wolff B, Zenke G: A novel antiinflammatory drug, SDZ ASM 981, for the treatment of skin diseases: in vitro pharmacology. Br J Dermatol 1999; 141:264-273

11 Gupta AK, Chow M: Pimecrolimus: a review. J Eur Acad Dermatol Venereol 2003;17:493 503.
12 Gutzmer R, Werfel T, Mao R, Kapp A, Elsner $\mathrm{J}$ : Successful treatment with oral isotretinoin of acneiform skin lesions associated with cetuximab therapy. Br J Dermatol 2005;153: 849-851.

13 Lacouture ME, Basti S, Patel J, Benson AI: The Series clinic: an interdisciplinary approach to the management of toxicities of EGFR inhibitors. J Support Oncol 2006;4: 236-238.

14 Matheis P, Socinski MA, Burkhart C, Warren S, Thomas NE: Treatment of gefitinibassociated folliculitis. J Am Acad Dermatol 2006;55:710-713

15 Alexandrescu D, Vaillant J, Dasanu C: Effect of treatment with a colloidal oatmeal lotion on the acneiform eruption induced by epidermal growth factor receptor and multiple tyrosine kinase inhibitors. Clin Exp Dermatol 2007;32:71-74.

16 De Witt CA, Siroy AE, Stone SP: Acneiform eruptions associated with epidermal growth factor receptor-targeted chemotherapy. J Am Acad Dermatol 2007;56:500-505.

17 Pomerantz RG, Chirinos RE, Falo LD, Geskin LJ: Acitretin for treatment of EGFR inhibitor-induced cutaneous toxic effects. Arch Dermatol 2008;144:949-950.

18 Segaert S, Van Cutsem E: Clinical management of EGFRI dermatologic toxicities: the European perspective. Oncology (Williston Park) 2007;21:22-26. 
19 Lacouture ME, Melosky BL: Cutaneous reactions to anticancer agents targeting the epidermal growth factor receptor: a dermatology-oncology perspective. Skin Ther Lett 2007;12:1-5.

20 Kimyai-Asadi A, Jih MH: Follicular toxic effects of chimeric antiepidermal growth factor receptor antibody cetuximab used to treat human solid tumors. Arch Dermatol 2002;138:129-131.

-21 Lee HM, Ciancio SG, Tüter G, Ryan ME, Komaroff E, Golub LM: Subantimicrobial dose doxycycline efficacy as a matrix metalloproteinase inhibitor in chronic periodontitis patients is enhanced when combined with a non-steroidal anti-inflammatory drug. J Periodontol 2004;75:453-463.
22 Nieman GF, Zerler BR: A role for the antiinflammatory properties of tetracyclines in the prevention of acute lung injury. Curr Med Chem 2001;8:317-325.

23 Lynch TJ, Kim ES, Eaby B, Garey J, West DP, Lacouture ME: Epidermaol growth factor receptor inhibitor-associated cutaneous toxicities: an evolving paradigm in clinical management. Oncologist 2007;12:610-621.

24 Luger T, Paul C: Potential new indications of topical calcineurin inhibitors. Dermatology 2007;215(suppl 1):45-54.

25 Jacobi A, Braeutigam M, Mahler V, Schultz E, Hertl M: Pimecrolimus $1 \%$ cream in the treatment of facial psoriasis: a 16-week openlabel study. Dermatology 2008;216:133-136.
26 Margolis DJ, Hoffstad O, Bilker W: Lack of association between exposure to topical calcineurin inhibitors and skin cancer in adults. Dermatology 2007;214:289-295.

27 Schneeweiss S, Doherty M, Zhu S, Funch D, Schlienger RG, Fernandez-Vidaurre C, Seeger JD: Topical treatments with pimecrolimus and medium- to high-potency corticosteroids, and risk of lymphoma. Dermatology 2009;219:7-21.

28 Mascia F, Mariani V, Girolomoni G, Pastore $S$ : Blockade of the EGF receptor induces a deranged chemokine expression in keratinocytes leading to enhanced skin inflammation. Am J Pathol 2003;163:303-312. 